\title{
Helicopter Accident Survivability
}

Maj P Vyrnwy-Jones,

MBBS, Dip Av Med, MSc, AFOM, RAMC.

Royal Air Force Institute of A viation Medicine, Farnborough

Maj R Thornton, MBChB, Dip Av Med, AFOM. MRAeS, RAMC

Royal Army Medical College, Millbank

SUMMARY: Army Air Corps accident and fatality rates have now reached levels which compare favourably with data from other civilian and military sources. This improvement is the result of enhanced helicopter design and parallel progress in $\mathcal{J}_{3}$ aircrew training. The introduction of new generations of turbine powered rotor craft has largely eliminated mechanical failure? as the cause of accident. As a result $75 \%$ of Army Air Corps accidents are due to pilot error. This contribution is likely to $\vec{\omega}$ increase in the future as the pilot's task is made more difficult by the incumberance of personal equipment.

Methods whereby occupant protection and aircraft crashworthiness can be improved are reviewed and it is concluded that it would make sound economic sense to implement some of these well proven design features.

\section{Introduction}

Serving members of the RAMC will all come into contact with Army Air Corps (AAC) helicopters at some stage of their career. Perhaps they will be involved with a casevac operation or even be asked to help in the initial stages of an aircraft accident enquiry. Whatever their background, few will have any idea of the safety record and survivability of helicopters. Most people regard helicopters as strange collections of rotors, gears and moving parts which stagger into the air by fortune rather than the use of aerodynamic principle. Some people refuse to fly in them at all, whilst others leap at any opportunity of a flight. Are the former group justified in their fears and the latter too optimistic? This article hopes to answer these queries and offer some insight into the way helicopter design, as far as crashworthiness is concerned, is progressing.

\section{AAC ACCIDENT AND FATALITY RATES}

\section{Terminology}

Rates for aircraft accidents and fatalities are quoted statistically in many ways; for instance as numbers of occurrences per $\mathrm{X}$ number of passenger miles flown, or as number of occurrences per number of take offs. The usual way, however, is to talk about the number of accidents or fatalities per 10,000 flying hours and this is the system used here. There are drawbacks, as one cannot always directly compare two different sources of information, as the definition of an accident will differ, but at present we are confined to this recourse as no other data are available.

\section{AAC Accident Rates}

Figure 1 represents the AAC accident rate from 1964-1982. As can be seen, there has been a rapid decline

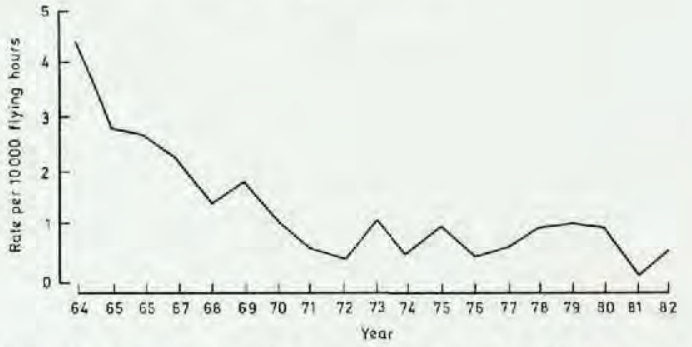

Fig. 1 Army Air Corps helicopter accident rates perô้ 10,000 flying hours $1964-1982$

over the years and the accident rate has apparently reached a plateau, running at an average rate of 0.73 per 10,000 ? flying hours since 1971 . The major part of this dramatic reduction is due to the phasing out of earlier less reliable reciprocating engined helicopters such as the Skeeter which one year had an accident rate of 9.2 per $10,000=$ flying hours, and the introduction of more modern tur bine powered aircraft such as the Gazelle and Lynx.

The AAC at present flies some 100,000 helicopter hour per year.

\section{AAC Fatality Rates}

A graphic presentation of AAC fatality rates since 1964 is shown in Figure 2. The surprising feature is that the fatality rate has not decreased concomittantly with accident rates and certainly showed signs of rising during the period 1978-1980. The possible reasons for this are the increased velocity at impact of modern helicopters coupl ed to their increased passenger carrying capability.

The overall fatality rate since 1971 is 0.26 per 10,00 (P) flying hours. 


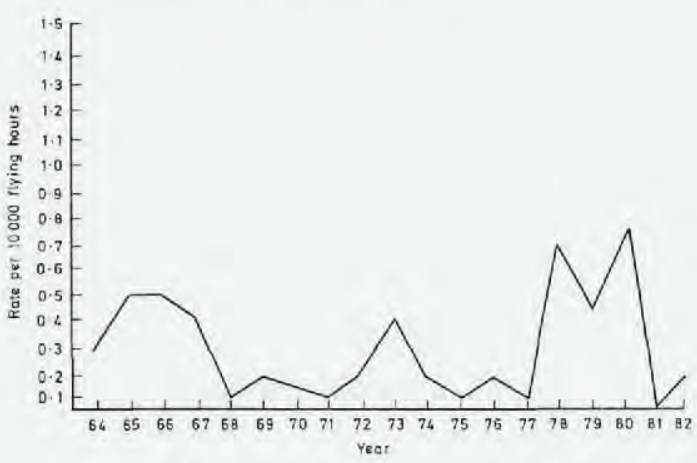

Fig. 2 Army Air Corps fatality rates per 10,000 flying hours 1964-1982

\section{Passenger Fatalities}

Since 1971 there have been over 90 AAC helicopter accidents with 34 fatalities. Fifteen of these fatalities (44\%) were accounted for by passengers. As discussed later, passengers tend to be more vulnerable when accidents do occur, as they lack protective helmets and occupy the rear seats with their less efficient safety harnesses. Approximately $45 \%$ of all accidents occur to helicopters which are carrying passengers.

\section{COMPARISONS WITH OTHER DATA}

\section{Historical}

Early aviators were prepared to accept much greater risks than their modern peacetime counterparts, but such attitudes are, of course, relative. H G Anderson ${ }^{1}$, in his excellent book 'The Medical and Surgical Aspects of Aviation', published in 1919, stated that at a UK flying school 58 major accidents occurred over a period of 4,000 flying hours, or one crash every 155 flights. This equates to an accident rate of 145 per 10,000 flying hours, but this of course relates to major accidents whilst modern figures include some quite minor occurrences. Anderson goes on to say that this is a fairly safe record comparing favourably with other forms of high velocity transport! Some of these early accidents were spectacular and Figure 3 demonstrates perhaps one of the most unique accidents in aviation history. The pilot survived the ordeal.

By the time of World War II aircraft had improved, but losses due to accidents outstripped those due to enemy action. A report ${ }^{2}$ of US Army Air Corps aircraft losses during 1943 demonstrates that 3,874 were lost in combat, as opposed to 5,024 destroyed in flying accidents. US Army helicopter losses in South East Asia totalled some 3,850 during the period 1961-1970. Of this total, 1,704 losses were due to accidents or other operational reasons.
It is perhaps not surprising that there is such a general interest in accident prevention. The AAC's current accident rate is at least 200 times less than that experienced during the pioneer days of aviation.

\section{British Military Data}

An earlier major review of British military helicopter accidents ${ }^{3}$ was based on the data collected from all three Services during the period 1960-1969. The accident and fatality rates were respectively 1.13 and 0.94 per 10,000 flying hours. This fatality rate was in fact three times higher than that of RAF ejection equipped aircraft $(0.34$ per 10,000 flying hours). However, these data were based largely on early types of helicopters which were not very reliable. The RAF's Belvedere had a very high fatality rate of 7.58 per 10,000 flying hours.

The introduction of modern helicopters has changed all this and current AAC fatality rates are lower than that

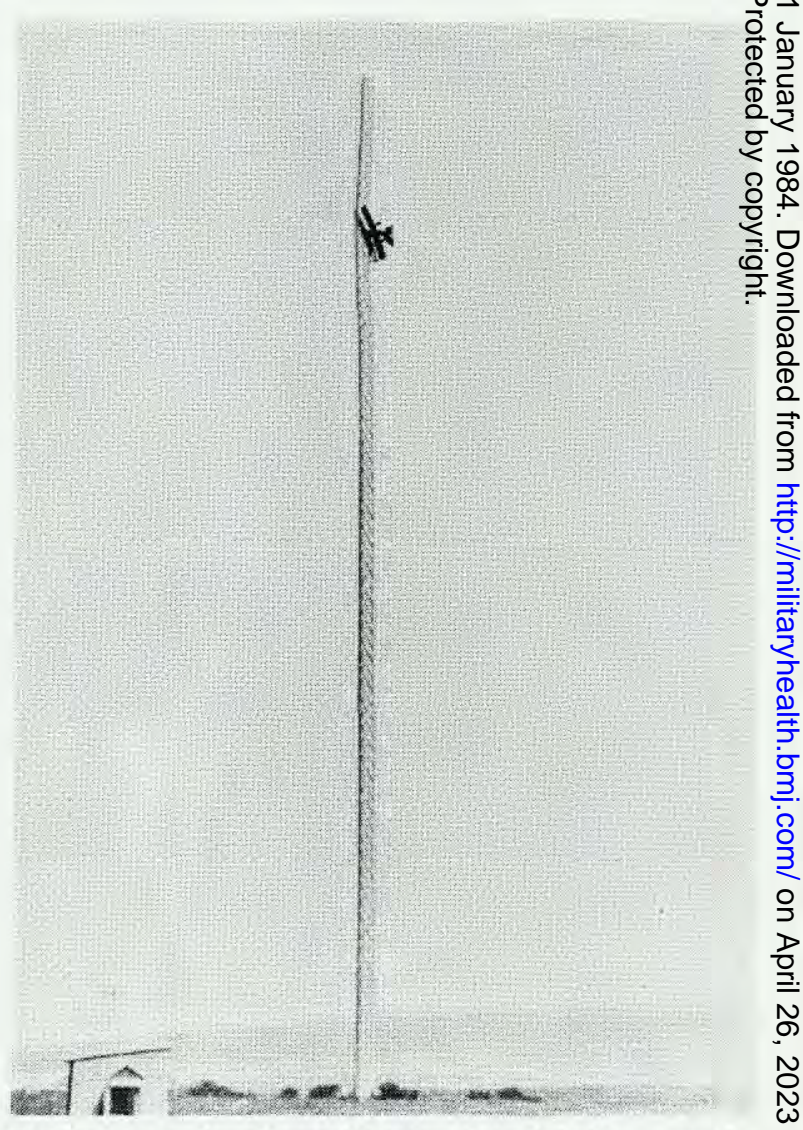

Fig. 3 A seaplane has collided and stuck in the mast of a wireless station. The pilot survived. 
of ejection equipped aircraft. RAF helicopter accident and fatality rates are now even less than those of the AAC.

\section{USA Data}

The United States is by far the largest helicopter operator, both civil and military, and a considerable amount of information is available from various sources. Military data ${ }^{4}$ show that, excluding Vietnam, US Army helicopter accident rates have levelled at 0.65 per 10,000 flying hours, a rate very similar to that of the Army Air Corps. Gilbert and McMahon ${ }^{5}$ carried out a survey of the fatality and accident rates for all USA general aviation (GA) aircraft and rotary winged aircraft for the period 1972-1980. The AAC fatality rate is slightly greater than either GA aircraft or helicopters alone, but the overall accident rate is 2.5 times less than that of USA rotorcraft alone. These differences probably reflect the high quality of military training and servicing and the use by the Army of the more reliable turbine engines. USA experience indicates that piston engined helicopters have 4-5 times the accident rate of turbine powered helicopters.

\section{OCCUPANT PROTECTION AND AIRCRAFT CRASHWORTHINESS}

The argument for and against providing impact protection to aircraft occupants in the shape of helmets and harnesses were bitterly contested in the early days of aviation in much the same way as the recent controversy over car seat belts. Many aviators considered that helmets would increase the likelihood of head injury due to the weight and thought that it was better to be thrown clear of an aircraft on impact rather than remain attached to the wreckage which was more than likely to be engulfed by fire.

Much experience was gained during the First World War and H V Wells ${ }^{6.7}$ in his papers of 1915 and 1916 advocated the use of helmets and harnesses to avoid injuries sustained during turbulence, aerial combat and the all too frequent accidents. Interestingly, he suggested the use of a combined lap and shoulder harness to prevent the head striking cockpit structures and the introduction of padded structures to reduce the effect of any such impact.

Several famous aviators of the period met their untimely deaths due to lack of a restraint system. Amongst these was the elegant Miss Harriet Quimby (Fig. 4) who was the first woman to fly across the Channel. She and her companion were killed when they fell from their aeroplane during a period of severe turbulence, whilst taking part in an aviation meeting at Boston in 1912. They plummetted 1,000 feet to their deaths in the sea below. The great Col S F Cody himself was killed when he was thrown from his aircraft after it started to break up in flight.

Unfortunately despite all the evidence and the recurring tragedies, it is only during the last decade that all of
H V Well's ideas have been implemented into militar helicopters.

\section{Restraint Systems}

All AAC helicopters, except for the Scout, have beers? fitted with combined lap and shoulder harnesses for passengers. The Scout rear seats still consist of a single lap belt. The apparent omission in the case of the Scou? is due to the unforeseen extension of its Army service $\frac{\bar{D}}{\bar{n}}$ Aircrew are all well restrained with a five point harnes: in the front seats.

Body motions associated with aircraft crash impact है are violent, even in accidents of moderate severity. The flailing of body parts is most pronounced when the oc: cupant is only wearing a lap belt, and when a lap-shoulde $\vec{\omega}$ harness is fitted there is still possible multi-directiona? flailing of the head, arms and legs and lateral displace ment of the upper torso from its restraint harness. Spach in current Army helicopters is at a premium and thes

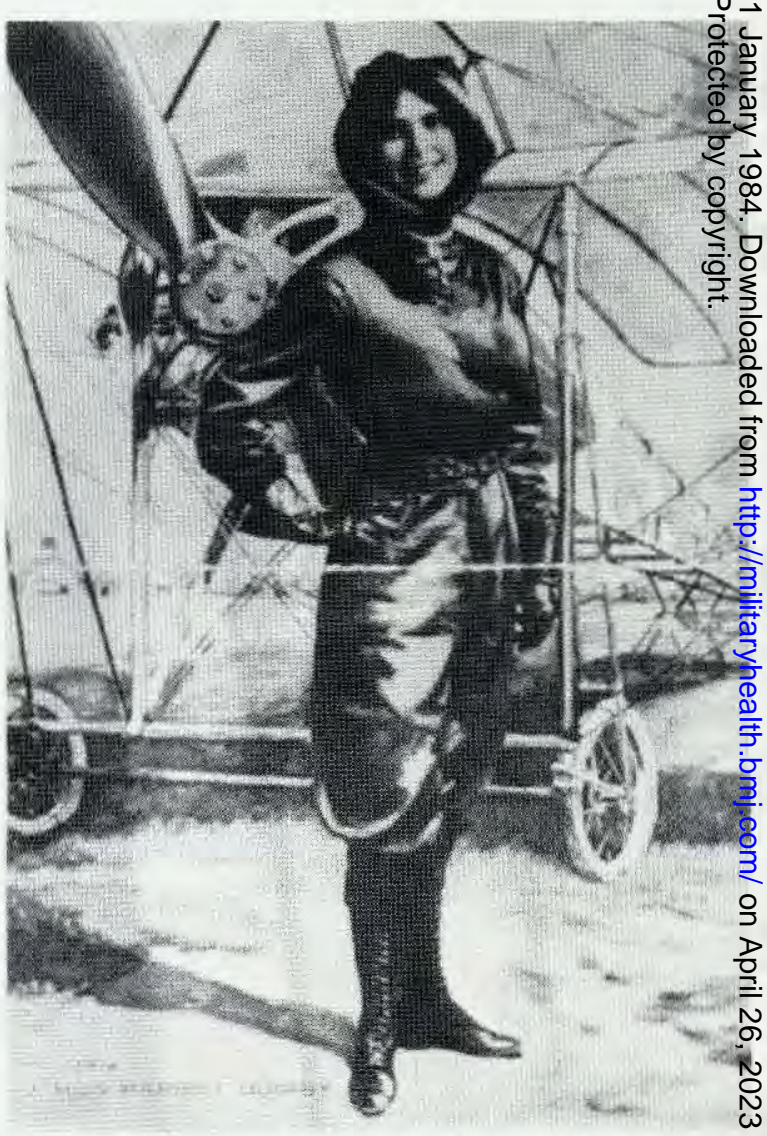

Fig. 4 The elegant Miss Harriet Quimby 
movements are bound to bring the occupant's body into contact with the aircraft structure. It is not feasible to remove major structural components, and we must rely on the most efficient restraint system available and, where necessary, direct protection as provided by helmets.

\section{Helmets}

The head has always been vulnerable in accidents and as man has improved the design of his helmet from animal hide to bronze, metals, composites and now multi-layered energy absorbers, he has at the same time, increased the velocity and force of impact. The first fatal head injury to occur in powered flight occurred on the 17th September, 1908 at Fort Mayer, Virginia, when a propeller failure caused the tail of the Wright Flyer to collapse and the aircraft dived in from 75 feet. Orville Wright suffered broken ribs and a fractured left leg, but Lieutenant F. Selfridge, US Army, died of a fractured skull. He was not wearing a helmet.

Current data ${ }^{8}$ based on US Army accidents involving 4,550 occupants show that head injury accounts for $31.5 \%$ of all fatal injuries and $19.7 \%$ of all major injuries. The type of helicopter involved appears to have little influence on the outcome and implies that head protection is important, not only in the AAC's light helicopters, but also in large load or troop carrying helicopters.

Analysis of injury data from the Gazelle, Scout and Lynx is shown in Figure 5, which represents the frequency of major and fatal injuries to different body parts. Head injury accounts for $25 \%$ of the total.

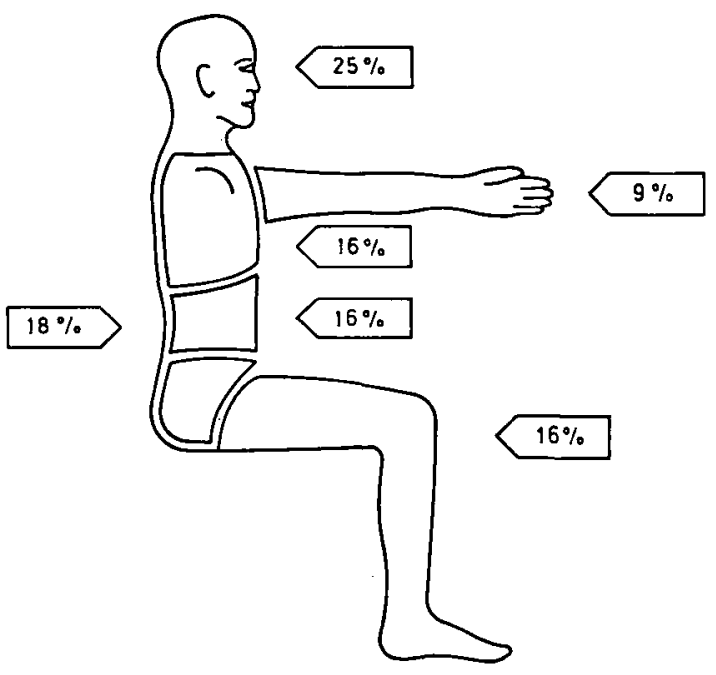

Fig. 5 Frequency of major injuries to body parts in AAC helicopter accidents, 1971-1982
Military pilots have been equipped with helmets from the earliest dates and helmets now serve as noise attenuators, communications systems, and mounting points for various items of military equipment. Passengers have not been so fortunate and undoubtedly many have met their deaths as a consequence. The head may be injured by contact with cabin structures, or if the passenger's harness fails and he is thrown clear his head will be extremely vulnerable to impact during his forced ejection.

The problem has always been that standard military helmets are expensive and individually fitted and also require a certain amount of training in their use. They are also bulky and there is little room to carry spare helmets for casual passengers. What is required is a passenger helmet that is easy to fit, store, transport and service, has facilities for communications, fits all sizes and is cheap. Unfortunately, no helmet at present exists which satisfies all these requirements and the development of a military passenger helmet should be hastened. At present research into passenger helmets has only a low priority, even though study of available data indicates that this coulde save more lives than anything other that the introduction of a new generation of crashworthy helicopters. It would be a comparatively cheap solution with no expensive air craft modifications being required.

\section{AIRCRAFT CRASHWORTHINESS}

To date the greatest reduction in helicopter fatalities and injuries has been achieved by improving the reliability of aircraft and the training of their pilots, but analysis of recent data demonstrates that military accident rates have reached a stable level and the majority of accidents are now due to human error. Seventy five per cent of AAC helicopter accidents are due to pilot error and only $13 \%$ to mechanical failure.

We can, therefore, expect accidents to continue occurring no matter how reliable the aircraft and aircraft systems become. To improve on the current accident and fatality rates we must look to improving the crashworthiness of our helicopter design. Army helicopters have a poor crash performance at force levels which are known to be well tolerated by human subjects when well restrained. Injuries are caused by seat collapse and crushing of the occupant space by heavy structures such as gearboxes and engines which are usually mounted above the passenger compartments. Fuel systems are also easily ruptured, resulting in the possibility of severe post crash fire if there is an ignition point adjacent to the spilt fuel. The American approach to this problem has been the introduction of a new generation of crashworthy helicopters, namely the UH60 Blackhawk and the Hughes Apache. These helicopters have crash resistant fuel systems which have almost totally eradicated the problem of post crash fire. They have energy absorbing undercarriages, airframe structures and crew seats and their engines and gearboxes are placed so that in the event of a major accident, the occupant living space is not intruded 
upon. A typical accident is one in which the aircraft strikes the ground in a flared (nose up) attitude with little forward speed but relatively high vertical velocity. In current UK helicopters this will result in breakage of the landing gear, often severence of the tail pylon and a damaged airframe with possible intrusion into the occupant space. In a crashworthy design, the impact will first be absorbed by the normal stroking* of the undercarriage followed by deformation of energy absorbing components of the undercarriage and lower fuselage. The crew seats will then begin to stroke if the deceleration is great enough, and absorb further energy. Crashworthy helicopters are designed to take an impact of $42 \mathrm{ft} / \mathrm{sec}$ in the vertical plane, without there being catastrophic damage to the aircraft. The occupants should also be able to walk away uninjured.

\section{Cost Effectiveness}

The chief argument against any improvement in helicopter crashworthiness is the prohibitive cost, unacceptable increase in weight and hence performance. This is used to counteract the argument of decreased injuries and fatalities which would result from improved helicopter design. It is, however, possible to put the argument on an economic basis. In 1971 a full scale study was carried out in the United States to determine the cost to the government to replace an aviator killed in a helicopter crash. This ranged from $\$ 102,670$ for a $2 \mathrm{Lt}$ to $\$ 759,954$ for a WO4. This, it is emphasised, refers to dollar costs in 1971 and allowance must be made for increased costs in training and, of course, inflation. Furthermore, improved aircraft crashworthiness will undoubtedly reduce material costs by minimising the amount of major airframe damage sustained in an accident. American experience is that although the production cost is high, the savings from reduced impact damage, fatalities and injuries more than outweigh the initial outlay.

\section{AIRCRAFT DECELERATION PARAMETERS AND HUMAN TOLERANCE TO ACCELERATION}

If we are to design any form of energy absorbing device or restraint system, we need to know a little of human tolerance to accelerations of short duration and the type of decelerations likely to occur in helicopter accidents. Most of this information comes from data collected by the US Army from accidents which occurred during the period 1971-1976 ${ }^{8}$.

\section{Aircraft Deceleration Parameters}

The curve in Fig. 6 shows the distribution of vertical (i.e. headwards) velocity, change in survivable rotary and light fixed wing aircraft accidents involving substantial structural or occupant injury. It can be seen that a 50th percentile accident equates to a velocity change of 24

\footnotetext{
* The controlled energy absorbing movement
}

$\mathrm{ft} / \mathrm{sec}$, whilst the 95 th percentile equates to a velocity $\underset{\mathbb{\infty}}{3}$ change of $42 \mathrm{ft} / \mathrm{sec}$. The corresponding figures for longitudinal velocity changes are $28 \mathrm{ft} / \mathrm{sec}$ (50th percen-o tile) and $50 \mathrm{ft} / \mathrm{sec}$ ( 95 th percentile). Lateral velocity changes have not been accurately computed, but it has been estimated that these changes do not exceed $25 \mathrm{ft} / \mathrm{sec}^{\text {s }}$ for a light helicopter. Using these figures it was possibleo to calculate the actual impact decelerations likely to beo sustained during survivable accidents. These are for the 95th percentile survivable accident, $24 \mathrm{G}, 15 \mathrm{G}, 18 \mathrm{G}$ in the vertical, longitudinal and lateral planes respectively.

\section{Human Tolerance to Impact Decelerations}

There are a multitude of factors which affect the $\overrightarrow{-}$ tolerance of the human body to impact forces. These in- $\omega$ clude age, sex and general health. Military aviators are usually much younger and fitter than the population for which impact tolerances were calculated. The criteria are? also based on a fully restrained individual correctly posi- $\overrightarrow{-}$ tioned in an upright posture, and a helicopter pilot is very? unlikely to be in such a position at the moment of in pact. This will undoubtedly reduce tolerance to impartu deceleration.

AAC aviators are now all well restrained with a fipepoint, shoulder and lap belt harness and it is unlikely that this restraint system can be improved upon significandy? in the near future. The negative $G$ or tie down strapo prevents rotating underneath the lap strap of the pelvis during longitudinal velocity changes. The aviator shouth $\infty$ of course, ensure that his harness is as tight as comf tably possible, in order to avoid the dynamic overshoftro phenomenon. During an accident the seat occupant's ertia will maintain him at a constant velocity indepen $-\overline{0}$

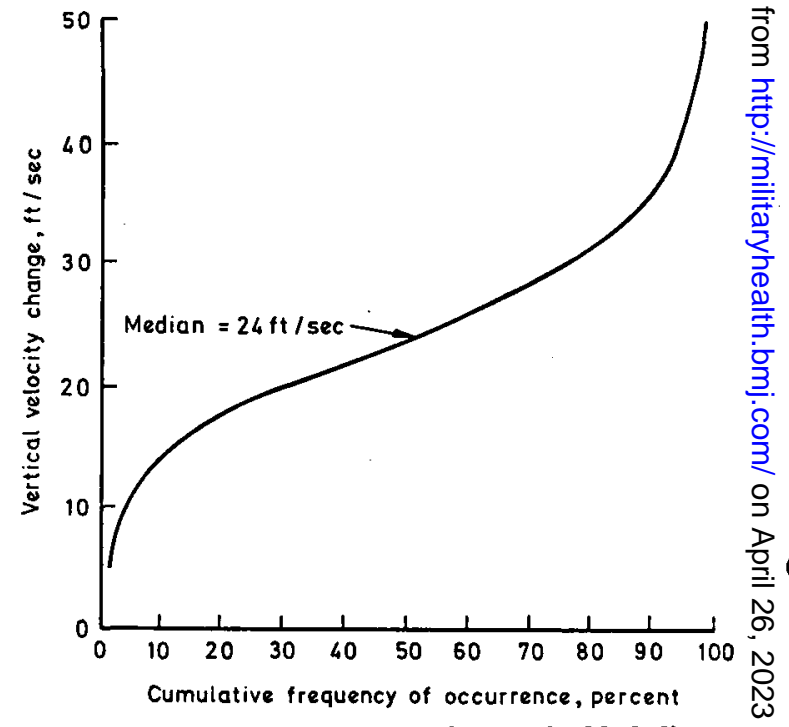

Fig. 6 Vertical velocity changes for survivable helicopte్ㅏㅁ accidents (Aircraft Crash Survival Design Guide Vol II) 
dent of the decreasing velocity of the seat until the restraint system slack is taken up. At this point the occupant's velocity is abruptly reduced to that of the seat, with resultant deceleration forces exceeding those of the seat alone.

The most critical velocity parameter is that sustained in the vertical plane. Human tolerance to headwards loading is significantly less than that to fore and aft acceleration, mainly because of the susceptibility of the lumbar vertebrae to compression fractures. Also forces acting parallel to the long axis of the body place a greater strain on the suspension system of the viscera.

\section{Methods of Reducing Impact Forces}

As we have seen, we can estimate the likely impact forces sustained in a helicopter accident and we know something of the human tolerance to these decelerations. Deceleration is, of course, inversely proportional to the stopping distance available, and though some of this distance is provided by the airframe structure and the impacted terrain, this may not be enough to reduce the forces to tolerable levels. We can achieve tolerable levels by increasing the amount of crushable airframe, using energy absorbing undercarriages and seating systems that allow controlled collapse to occur. It is prohibitively expensive to fit new undercarriages or major air frame modifications on aircraft already in service, but crashworthy seats can be fitted, and indeed have been, to many aircraft. The next generation of UK helicopters may be fitted with crashworthy seats and the future commercial sales possibilities in the USA will be hampered by the lack of crashworthiness of current European helicopters. It would, therefore, be beneficial to discuss energy attenuating seats further.

\section{Energy Absorbing Seats}

The idea of an energy absorbing seat is to attenuate the energy reaching the occupant by a controlled deformation. The energy must be absorbed at force levels which are within the defined human tolerance limits. The seat does not absorb all the energy, most of which is absorbed by earth, airframe and stroking of the landing gear. It must be remembered that the same stroke distance is required to decelerate different masses at a given deceleration force. Hence lighter aviators do not require less stroking distance, they require the same as heavier personnel. Unfortunately, a 100lb occupant would require approximately twice the deceleration of a $200 \mathrm{lb}$ occupant before a crashworthy seat would begin to stroke. This problem has been overcome by providing adjustable energy absorbers to account for the weight of the occupant.

\section{Current Energy Absorbing Devices}

There are a lot of energy absorbing seat designs now extant. These include wire bending devices, inversion tubes, the rolling torus, crushing honeycombs, tube flaring and rod pull-through tube devices.
To illustrate some of the principles employed we will discuss the wire bending device and rod pull-through devices. The wire bending device is currently in use in the RAF Chinook fleet and is at present the only crashworthy seat used in the British Forces.

\section{Wire bending energy attenuators}

Wire bending energy attenuators use the force required to bend metal wire around a die or a set of rollers. The Chinook employs a system of wire energy attenuators and the aircrew can select the number of wires used, depending on their weight. To date no RAF Chinook has crashed and the system has hence never really been tested.

\section{Rod Pull-through Systems}

This attenuation system consists of metal rods which are located in dies in the vertical axis. On impact the attenuating rods are forced through the dies, changing the rod diameter and absorbing energy in the process. A weight control lever engages, or disengages, rods into the system thereby catering for different occupant weight parameters. Martin Bakers employ this system in theife proposed armoured crashworthy helicopter seat.

\section{ASSISTED ESCAPE FROM HELICOPTERS}

For many years it was considered that the way forwar in reducing helicopter fatalities would be provided by us of an escape system analagous to the current ejectiog systems fitted to high performance fixed wing aircraf Some of these methods are illustrated in Fig 7. Contrax产 to popular belief, parachute escape from helicopters is perfectly feasible and is possible even at high rate of descent and in unusual attitudes. Indeed, at present, the Navy are actively investigating the introduction of parachute escape systems to some of their existing helicopters. However, none of the other systems could be easily fitted to present AAC helicopters. The ejection and extraction systems offer the best hope for the future, because of the high weight penalty of other systems. Even so, it is doubtful if these systems could be adapted to fit passengers and this could leave the crew in the difficult position of having to elect to leave the aircraft with its complement of helpless passengers.

A significant proportion of AAC accidents since 1971, have occurred to helicopters on the ground or in the hover, or were the results of controlled fly-ins. These account for $64 \%$ of the total accidents; most of these accidents would render assisted escape extremely difficult. An analysis by the author of all 89 accidents indicates that of the 20 accidents with fatalities, there are 7 where 11 lives could have been saved assuming a perfect escape system. Five of these accidents refer to disorientation errors and it is by no means certain that an escape system would have been used in all these cases. Nineteen of the accidents resulted in salvageable aircraft and these caused only 3 minor injuries. Had an escape system been 


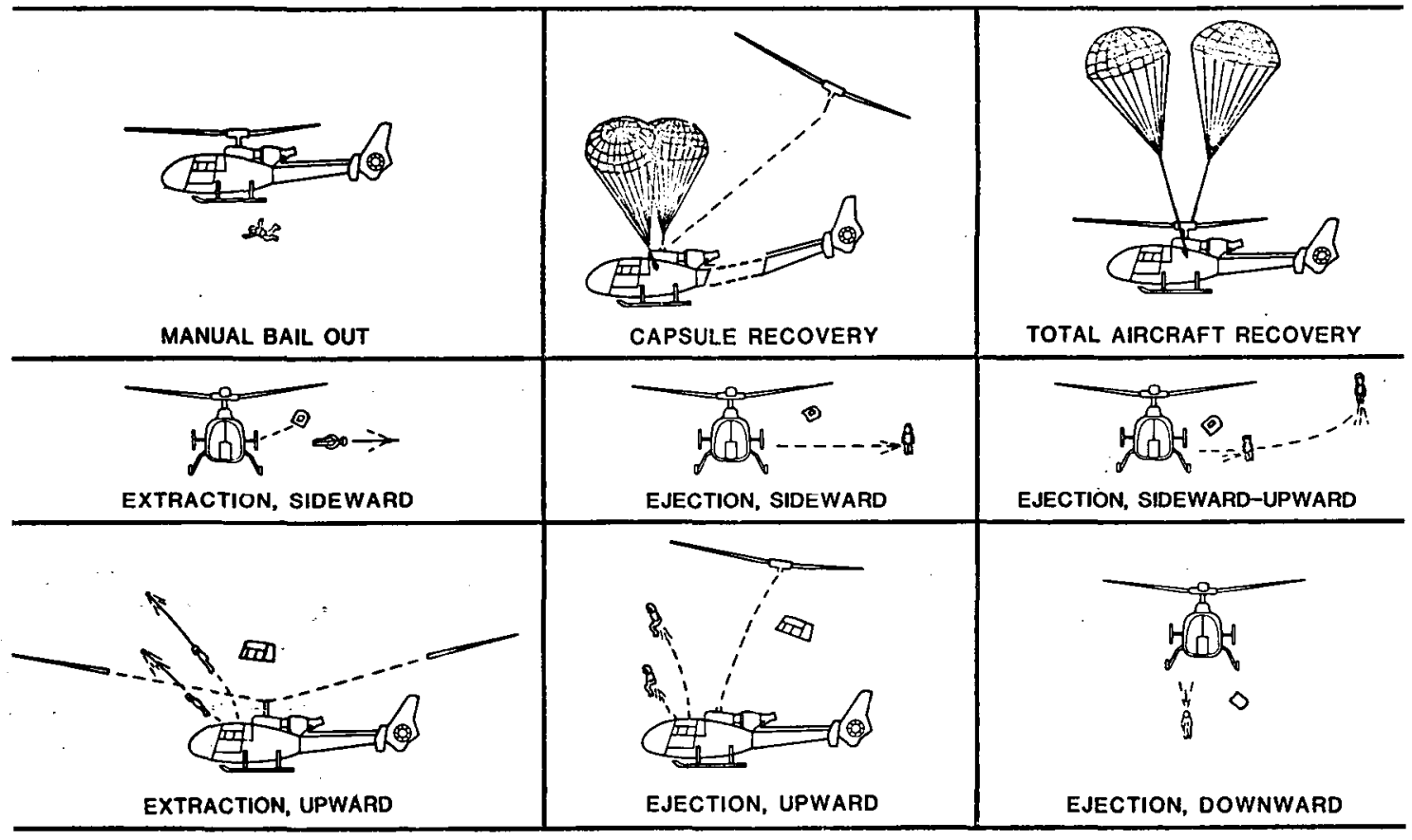

Fig. 7 Escape measures for helicopters

available and the pilots elected to use it, the result would be 19 total losses and a probable increase in the number of injuries sustained.

\section{Investigation of Accidents}

Every accident teaches something new, and all should be investigated, so that preventable causes may be eliminated and improvements suggested for future aircraft design. Areas where accident investigations have contributed directly to aircraft and aircrew equipment modifications are helmet and harness design and other personal protective equipment and in the case of US helicopters, the introduction of crashworthy airframes, seats and fuel systems. If this progress is maintained the tragic fatalities and injuries associated with accidents can be decreased with potential large savings in defence budgets and human suffering. Decreasing the accident rate itself presents more of a problem. As already stated $75 \%$ of all Army helicopter accidents are due to human error of one type or another and the human factors aspect of aircraft investigation has now become important. Any further major decrease in accident rates can only come from the solution of the human error problem.

\section{Conclusions}

So, how safe are Army helicopters? Certainly the record compares very favourably with civilian data and\% is comparable to other military sources. At present when $\underset{\varnothing}{\varnothing}$ flying Army aircraft, there is a risk of one accident every $\vec{\overrightarrow{ }}$ 13,600 flying hours and a fatality every 37,500 flying 3 hours. There is every reason to suppose that accident rates? will decrease, but the introduction of crashworthy features: and passenger helmets would undoubtably save many lives in the future. There is also no doubt that there would be a major financial saving in equipment and human costs.

\section{REFERENCES}

1. ANDERSON, H G. (1919) The medical and surgical aspects of aviation. Oxford Medical Publications. Chapter VI.

2. ZeLLER, (1979) Three decades of USAF efforts to reduce human error accidents 1947-1977. AGARD Conference
Proceedings No. 254. B1.-B1.9.

3 DAY, E E. (1972) The case for helicopter assisted escape. Royal Aircraft Establishment Technical Report No. 72120.

4 WATERS, K T. (1977) Research requirements to improve the safety of civil helicopters. NASA CR-145260.

5. Gilbert, G and McmahoN, B. (1982) How safe are을 helicopters? Business and Commercial Aviation 61-66.

6 WeLLS, H V. (1915) The flying service from a medicalos point of view.J $R$ Nav Med Serv 1.

7 WELLS, H V. (1916) Some aeroplane injuries and diseases, with notes on the aviation service. $J R$ Nav Med Serv 2. $\omega$

8 Aircraft Crash Survival Design Guide Vol. II. (1980). Air-O , 